\title{
Northwestern Tanzania on a Single Shilling: Sociality, Embodiment, Valuation
}

Brad Weiss

College of William and Mary, blweis@wm.edu

Follow this and additional works at: https://scholarworks.wm.edu/aspubs

Part of the Social and Cultural Anthropology Commons

\section{Recommended Citation}

Weiss, Brad, Northwestern Tanzania on a Single Shilling: Sociality, Embodiment, Valuation (1997). Cultural Anthropology, 3, 335-361.

https://doi.org/10.1525/can.1997.12.3.335

This Article is brought to you for free and open access by the Arts and Sciences at W\&M ScholarWorks. It has been accepted for inclusion in Arts \& Sciences Articles by an authorized administrator of W\&M ScholarWorks. For more information, please contact scholarworks@wm.edu. 


\title{
Northwestern Tanzania on a Single Shilling: Sociality, Embodiment, Valuation
}

\author{
Brad Weiss \\ Department of Anthropology \\ College of William and Mary
}

\section{An Aesthetic of Objects and Bodies}

The process of fermenting banana juice and ground millet into banana beer is an elaborate craft, practiced and appreciated by Haya men. As is the case in many African communities where the plenitude and desirability of beer is intimately connected with, if not indistinguishable from, the establishment and vigor of sociality itself, Haya brewers and drinkers are scrupulously attentive to the details of this often lengthy procedure (Carlson 1989; Karp 1980; Taylor 1991). ${ }^{1}$ Many told me of their concern that jealous neighbors or sorcerers (often one and the same in Haya neighborhoods) would spoil their efforts by pouring kerosene into the frothy mixture during the night. But Haya evaluations of the fine points of the brewing process are by no means limited to anxious attempts to safeguard their valuable libations; there is, in fact, what can best be described as an aesthetic of beer production, and it is the demands of this aesthetic that dictate a careful and precise technique.

Haya brewers say that it takes three days to prepare olubisi (fresh) banana beer from the juice of special beer bananas fermented with ground, often roasted millet. ${ }^{2}$ The beer is stored in the dugout canoe (obwato) in which the banana juices are first extracted, and must rest overnight and then the entire next day (the second day) before being ready to serve on the following morning (the third day). Over the course of these days and nights, samples from the developing mixture are frequently tasted to scrutinize and savor the brew. It is especially important to test the beer on the second day, when the millet has begun to draw the sugars out of the banana juice but has not yet fully converted them into alcohol. This heady, oversweet concoction, having rested for one full day after being squeezed, is called omulala (the sleeper) and is a highly prized drink in its own right. One man even described a well-made omulala as "a gift for a king." But omulala is not only enjoyed for its own sake, since it is taken as a critical index 
of the quality of beer that will be served the next day. Tasting omulala provides the occasion for gauging the progress of the overall beer-making process.

And it was on one such occasion-the cover having been lifted from the dugout canoe that held the fermenting banana juices in order to consider the prospects for the next day's beer-that a brewer, along with several of us who had helped him prepare the brew on the previous day, was stunned to taste a less than admirable omulala. The mixture, in the judgment of many who tasted it, was just too thick and syrupy to hold the promise of tomorrow's good drink. The beverage "was viscous and slippery," and that meant that the next day it would be harsh and perhaps unpleasant. The olubisi would "tear" (okugutuka) the throats of those who drank it, said one neighbor, while slashing with his forefinger across his neck, an ominous gesture that I had seen Haya drinkers make before. There were, however, some well-known remedies to this immanent danger. The anxious brewer and assembled friends told me that the thickened mixture could be doctored by dropping a single shilling coin into the canoe and allowing it to remain in the brew overnight. One man took out a five-shilling coin and offered to toss it into the mix, but that was shouted down as inappropriate; a single shilling coin was the only effective denomination (see Figure 1). Once the coin was in place, an alternative secondary remedy was proposed. A "young girl who is still a young girl" could be lifted over the canoe, from one side of the vessel to the other, and this, too, would save the ill-fated beer. The next-door neighbor went home to get his three-year-old daughter and returned to carry the clearly frightened little girl across the beer-laden boat.

How might the efficacy of these procedures be accounted for? What do small change and small girls have to do with brewing better beer? I asked a neighbor who had helped with the beer why the child had been used in the manner described; he grinned and said a young girl like this "has no flaws" (S. hana makosa). Another friend, a teacher at a local primary school with a secondary education, as well as the son of a beer brewer of no small renown, assured me (in English) that "scientifically" the shilling coin would effectively transform and improve the quality of the olubisi, as the "acid" in the metal could clearly stabilize the fermentation process. When I pressed him further, he said he also knew that carrying a young girl over the canoe was just as effective a technique but could offer no scientific reason why this should be so.

It might be argued, to follow the logic and language of certain contemporary perspectives, that coinage and such local beers are equally tokens of alternative "regimes of value": the former the quintessential medium of depersonalized, independent market transactions and the latter the principal medium of intimate, interdependent neighborly relations (compare Gregory 1982; Taylor 1991). Given this opposition, the convergence of these media-that is, the shilling that renders palatable the community's brew-could conceivably be assessed in terms of a nifty set of structural inversions: to wit, the icon of social intimacy gone (or going) bad is redeemed by its very antithesis, the currency of alienation. Of course, like the teacher's explanation, this "scientific" assessment of coinage remains baffled by the young girl's powers. Moreover, the principal 

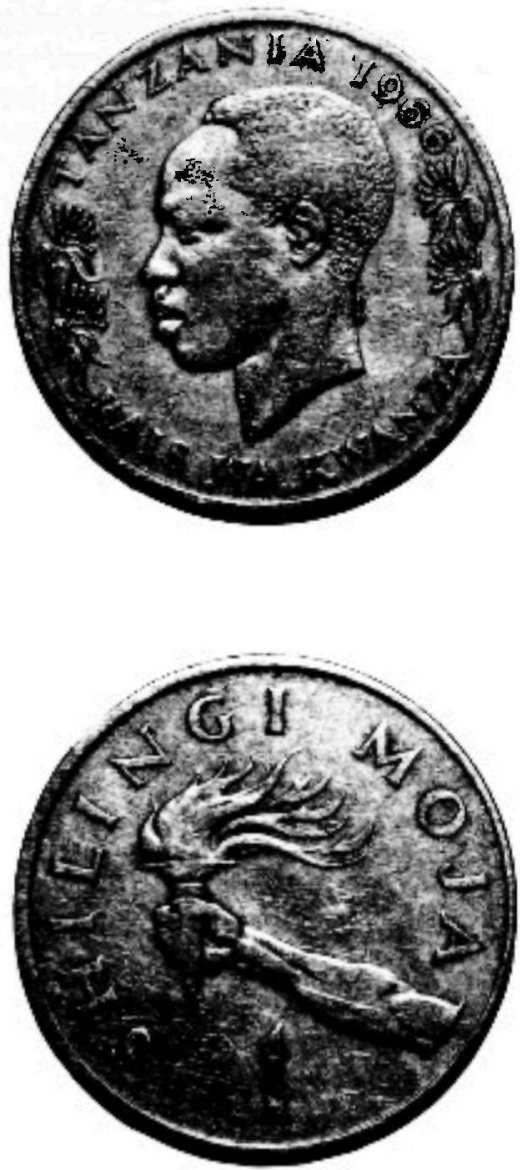

Figure 1

Both sides of a Tanzanian single shilling. Photograph reproduced courtesy of Michael Horner.

difficulty with such an analysis is that, throughout contemporary African communities, urban and rural - and particularly in Haya communities in the Kagera Region of Tanzania-beer is one of the most ubiquitously marketed commodities. And while small coins do not always figure in this stage of the fermentation process, hard cash is (with some important exceptions) always used to pay for the potable products of that process.

The purpose of this article, this lengthy prelude notwithstanding, is not merely to provide an adequate explanation for these occasional practices associated 
with Haya beer brewing. Nor is it, in spite of the welter of associations already detailed, meant strictly to present an interpretation of the symbolic resonances and divergences between money, sexuality, and drink. Rather, I aim to develop an account of how Haya sociocultural practices engage material objects, and I assert that these practices can be understood both to imbue those forms with value and to concretize characteristically Haya modes of bodiliness. I argue here that valuation and embodiment are intrinsic, and intrinsically connected, dimensions of sociocultural activities that generate an object world.

Such a perspective may be understood as part of an emerging reconsideration of "the body" and embodiment more generally. There are a spate of anthropological analyses, both classic and contemporary, that focus primarily on the body as either a "repertoire" of symbolic devices to be appropriated for social and cultural projects or a site for the inscription of hegemonic controls. ${ }^{3}$ Important as the insights of these analyses are, such positions often seem to presume the a priori objectification of "the body" as a form that may be subjected to the agency - both symbolic and pragmatic-of apparently extrinsic, that is, nonbodily, sociocultural forces. The approach I develop here, instead, views bodiliness as a "material process of social interaction" and, thus, a fundamental form of "practico-sensuous activity" (Turner 1994:29, 36; see also Marx 1959:244). In this view bodiliness, or embodiment, is not simply "culturally constructed," if such an assertion implies the independence of "cultures" whose actions produce "bodies." Rather, bodiliness-understood as a general capacity for inhabiting a given environment and as a mode of being-in-the-world-might productively be seen as "the existential ground of culture" (Csordas 1990, 1994). Embodiment in short may be examined as a world-making process through which meaning, significance, and value are generated, concretized, and experienced. This should not be taken to suggest, however, that "the body" or even the condition of embodiment is somehow precultural. While embodiment may be a condition that makes intentional social activity possible, it is reciprocally true that all embodied practices are configured by the lineaments of the meaningful and material contexts in which they take place. As "our general medium for having a world" (Merleau-Ponty 1962:146), the body always finds itself engaging in a specific world, an order of orientations, motivations, and potentialities that has been produced by, and serves in turn to generate, bodily practices (Hanks 1991:81-83). If we foreground exactly this engaged and situated character of all sociocultural activities, bodiliness might effectively be assessed as a capacity that conjoins and thereby collapses the distinction between the body as an object like any other in the world and a transcendent subject that produces a world through intentional acts.

Precisely because I am interested in such phenomenological processes as a means of theorizing about embodiment and its relations to cultural forms and transformations, I can only examine these processes in terms of specific forms of embodiment: particular, concrete, and (I will argue) characteristically Haya ways of being in the world. I suggest, for example, that Haya experiences of bodily well-being (a condition that is clearly challenged if not disrupted by such 
throat-tearing beer) are articulated in terms of sociocultural modes of embodiment that emphasize the ways in which bodily integrity is achieved through the synthesis of differentiated components. Haya bodiliness does not presume, I will argue, the intrinsic "unity" of the body but foregrounds the necessity of both differentiation and integration to achieving bodily well-being. The engaged character of the active, dynamic body is closely connected in Haya experience and action to the successful integration of the body's differentiable parts.

In this article I will also suggest that these perspectives on Haya bodiliness are of particular significance when examining the relation between subjects and objects in a context of changing social and cultural realities, because they permit us to explore the connections between objectification and embodiment. Many analyses point to the contrasts between objectification and embodiment as opposing modes of construing knowledge, meaning, and value-modes that are often characteristic of (purportedly) different forms of economy and society. Bourdieu, for example, offers sensitive readings of Kabyle embodied practices, seeing the body itself as the foundation for the habitus that makes cultural production and reproduction possible. Yet his examination of changes in the economies and lived worlds of Algerians emphasizes the objectifying effects of modernity on (for example) relations of exchange or agricultural production in contrast to the embodied dispositions of the habitus (Bourdieu 1979). The evidence from Haya sociocultural practices, by contrast, indicates that objectification is not an alternative to embodiment but a process that becomes possible as a consequence of bodiliness itself. I suggest, then, that the pattern of difference and synthesis characteristic of Haya bodiliness might usefully illuminate their sociocultural processes of objectification and valuation as well. Such a perspective allows us to consider the interconnectedness of embodiment, objectification, and valuation and of the ways, for example, in which specific Haya concerns with health and well-being resonate with their understanding of monetary values. If, as Merleau-Ponty suggests, "[o]ur perception ends in objects" (1962:323, emphasis added), then our objects and the values with which they are endowed emerge from the situated character and lived experience of the body in the world; that is, they are concretized through this capacity for embodiment that is the foundation of perception. From this perspective, then, the single shilling placed in the beer canoe and the young girl carried over it are less symbolic practices that need to be made sense of-or explained with reference to alternative, underlying, or fundamental forces or structures-than they are concrete instances of objectification and valuation generated as specific dimensions of Haya bodiliness.

\section{The Woman in the Canoe}

Consider the body's relationship to the brewing process I have described; it is a powerful relationship by no means limited to young girls' contribution to improved fermentation. Indeed, one of the things that is noteworthy about this particular contribution is the degree to which it seems to contradict routine bodily associations with beer. In Haya communities, as distinct from most other 
African contexts, beer is produced almost exclusively by men; and even in those few instances where women do provide the resources for beer production and control the final product, the actual substance of that product must be made by male bodies, hired or otherwise, made to carry out this task. In order to extract the sweet juices of beer bananas in sufficient quantity to provide olubisi, the ripened bananas are placed in a large dugout canoe together with grasses taken from the savanna that surrounds a village. This sticky mixture is then stomped on repeatedly until the juices from the bananas begin to be drawn out. These juices are then dipped from the canoe into one of many possible containers: anything from plastic buckets to 100 -liter oil drums to smaller canoes. As the bananas become increasingly desiccated, water will be added to the large canoe in order to trample and squeeze as much juice as possible from the fruit.

This squeezing process must always, according to Hay a brewers and drinkers, be carried out by a man. The erect position of the body in the canoe, the vertical insertion of the "juicer" into the banana morass, and especially the highstepping action of the stomping procedure itself-all of these are instantly recognized by Haya men and women as expressly masculine postures. Haya men's dancing styles, their characteristic agricultural activities directed toward the produce of tall trees, and even their ideal body shape emphasize a command of vertical space (Seitel n.d.; Weiss 1996b). It is, however, not only the spatial dimensions of this trampling that make it appropriate that men carry it out, for according to Haya men and women, it is imperative that women not be permitted to perform this activity. If a woman were to climb into a canoe for this purpose, it was often suggested to me, people would be worried that she might be "giving out blood" that would end up in the beer. Menstruation, which from many Haya men's perspective is less a regularly recurring phenomena than an ever-present problem of "femaleness," poses a clear threat to this process because it demands the vertical positioning of the body over and directly in the juicy concoction. It becomes especially ironic, then, that a possible remedy for certain crises of beer brewing involves passing a girl above and over the fermenting juices, thereby directly exposing them to what might otherwise be considered a possible contaminant.

Of course, a "young girl who is still a young girl" will not yet have begun to menstruate. Nonetheless, her presence in this situation and, specifically, her "elevated" position in the procedure indicate a certain challenge to routine expectations. What makes this challenge efficacious, and what might this reveal about the gendered dimensions of both Haya embodiment and objectification? When I posed the apparent anomaly of this technique to a group of friends, they told me that the canoes in which beer is made are "feminine" (ekikazi). "Haven't you seen," one of them slyly put it, "that women have their "canoes,' too?" The connections between beer canoes and women, even female genitalia, are noted in a range of contexts. The woodworker who makes the canoe, for example, avoids having sex on the days he is hollowing out the tree trunk. His restraint both prevents an injury to himself that might be caused if he were to lose his grip on the sharp tools of his trade and is held to keep the canoe from splitting as it 
is being dug out. The use of sharp, metal tools is both characteristic of men's productive activity-from pruning dried banana plant husks to hunting game-and can describe masculine sexuality. Spearing/culling (okuchumita) and slashing/harvesting (okutema), for example, not only are important and exclusively male activities carried out with iron implements but are also colloquial terms for men's sexual actions and experiences. It might be said, therefore, that the woodworker restricts his sexual activity while constructing a canoe because this process of construction replicates, in many respects, male sexuality itself.

The beer canoe is "feminized" by the process of its production and also by the productive processes the well-crafted canoe makes possible. Banana juices are stored for the fermentation process, along with ground millet, in the same canoe in which they were extracted. This refilled canoe (given the concerns with both possible malefactors and the details of the beer's development already described) is carefully and tightly wrapped and then concealed inside the brewer's house. This process is called okualika (to welcome in, to sequester) the beer, the very same term that is used for "welcoming" and acclimating a new bride. ${ }^{4} \mathrm{Haya}$ brides are usually brought into their marital homes literally "under wraps," covered from head to foot with kanga, or kitenge, cloth in order to protect her from the gaze and undue attention of outsiders. In her new home she will remain sequestered inside the innermost rooms of the house. Ideally, Haya men and women say that the bride should become pregnant during this period, which can extend up to a full year in some cases. The canoe, then, like the bride, is carefully concealed within the (male) house, replete with developing and powerful possibilities.

\section{Sociality, Integrity, and Division}

Given these explicit associations, it might be argued that while women are excluded from the physical preparation of olubisi, this exclusion actually arises not simply from the antipathies between the female body and the craft of beermaking but from the way in which these two can be likened to one another. Woman not only "have their 'canoes,' " but canoes, in effect, are women in the houses of the men who "welcome them." This likening of women to canoes as a grounds for keeping the two distinct suggests an important kind of relationship, one with profound implications for both embodiment and objectification. As one man put it, carrying a young girl over the canoe is effective because the canoe is her totem (omuzilo, pl. emizilo, literally "thing to be avoided," from okuzila, "to avoid"). Without entering into long-standing debates about "totemism" as an institution, I will address Haya accounts of the implications of their totemic practices, in order specifically to indicate these practices' relevance for understanding embodiment as a feature of sociality. A totem, for Haya men and women, is an object-often, but not always, an animal-that a person feels obligated, as the vernacular term makes clear, to avoid. This avoidance may take a number of explicit forms; for example, one should not eat or even touch one's omuzilo. Totemic relations are generally, but not uniformly, associated with clan affiliations. Yet totemic relations are certainly not simply "mapped" onto 
Haya social groups; people who recognize themselves to be members of the same clan will often avoid different totems, and the same totems are avoided by those who identify themselves as members of different clans. Indeed, as the claim that "a canoe is a woman's totem" suggests, totemic relationships are not necessarily associated with "clanship" itself. Totemic relations, then, are not just constituted by a "resemblance" between the systematic differentiation between Haya emizilo and the analogous differentiation of Haya social groups (Lévi-Strauss 1962:77). Emizilo do, however, instantiate some of the ways in which relationality is constituted in Haya social life. They reveal, I would argue, precisely how differentiation is defined as a feature of sociality itself.

Totems are fundamentally features of identity. It is because you are a member of the Babago clan, a spirit medium, a noble, or a woman that you recognize your particular omuzilo. Yet totems do not simply "mark" a distinctive, socially defined identity; rather, they establish the intrinsically relational character of identity itself. As the example of the beer canoe-an object that is a bride and that (therefore?) no Hay a bride could actually make use of-illustrates, totemic figures define identity as both integrated and divided. For if such totems are something with which those who recognize them closely identify, they are also something they must carefully distinguish themselves from.

This intrinsic complementarity of Haya identity might be seen in the woodworker's avoiding sex on the days he crafts a canoe. As we have seen, the tools and activities of this craft may explicitly suggest, or be used to describe, male sexuality. Yet spearing, chopping, slicing, and the like are generally characteristic of most rural Haya men's quotidian life, and as agricultural practices these do not impose restraints on the sexual activity of those who carry them out (and if they did, surely a lot less work would get done). Indeed, the performance of these activities, especially in relation to harvesting and providing food for a household, are typically felt to enhance a man's sexual appetites. What makes the carver's practice distinctive is that through his work, he also creates an actual "bride," a canoe. The canoe maker experiences and defines his sexuality, both its extent and its limits, through the complementary difference between men and women that his action produces. Unlike the agricultural worker's tasks, then, the woodworker's activities are not just expressive, or even constitutive, of masculinity, for the product of his hacking and slicing and cutting makes sexuality itself possible. In effect, sexual activity becomes the canoe maker's "totem" because the very grounds of sexuality-its identity defined as the difference and relationship between men and women-is generated by his actions. Canoe-making, then, is directly identified with the complementarity of sexual relations and, in keeping with the dialectical pattern of Haya sociality, must therefore be kept separate from them.

These dialectical dimensions of Haya sociality - the conjunction of unity and differentiation, integrity and alterity - that underly totemic relations may equally be seen in the consequences for violating the avoidances they require. According to the nearly uniform accounts of my informants, if a person were to kill, eat, or even, by some reports, inadvertently come into contact with their 
totem, "all of their skin would fall off!" This kind of affliction, widely reported in other parts of Africa as well, may be seen as an embodiment of the relational qualities of identity that $I$ have been describing. The surface of the skin provides a tangible medium for demonstrating both the individuation of the human form and the integration of the body into collective life. It is not trivial to note that skin surfaces create an appearance, for appearances, in Haya sociocultural practice, are aspects of the person that are available for others to observe and even scrutinize. Among Haya neighbors the appearance of a person's skin, its eruptions or clarity, dullness or brilliance, is generally taken - and widely commented on-as a reliable indication of that person's internal health and well-being. The surface of the skin may also, of course, be prepared so as to establish and demonstrate social connectedness, for example, as when mourners collectively shave their heads or members of a women's association dress in identical outfits. The skin is a prominent, in some ways privileged, bodily attribute in Haya discourses and practices through which the body is simultaneously inserted into social activity and discourse and differentiated from the world around it, including other bodies in the world (see also Devisch 1985; Weiss 1996a). This pattern is especially manifest at mortuary procedures. Not only do mourners shave their heads so as to "show" that they are "kin" to the deceased, they are also especially concerned to prevent ruptures, abrasions, or blemishes in the surface of the shaved head. The skin surface in this instance reveals both social connections (of mourning) and bodily integrity (of an uninterrupted, smooth scalp) as dimensions of a single social process. ${ }^{5}$ And it is precisely these qualities that are, as Haya commentaries make explicit, literally breached when a person violates their totem, for the destruction of the skin reveals the collapse of the connection between integration and separation which the skin embodies, and totemic relations objectify. That these qualities of the skin and its integrity are directly conjoined to the experience of totemic avoidances suggests an underlying pattern in Haya sociality, a pattern that generates identity itself as an inherently and internally relational attribute.

\section{The Well-Being of the Partible Body}

What do totems and their taboos have to do with the body's participation in processes of objectification and valuation? How do the particularities of Haya sociality further our understanding of the specific practices and processes under consideration? My exploration of these questions shows us that Haya constructions of social identity problematize issues that have to do with integrity. These constructions render implicit division intrinsic to enduring coherence. In what follows, I suggest that the implications of these apparent paradoxes of identity and integrity may be traced through some fundamental Haya understandings of both the body and money, as well as their occasional conjunction in social practice and experience.

The very term for "body" in the Haya language, omubili, is linguistically related to the word ebili (two). ${ }^{6}$ Such a derivation suggests, perhaps fortuitously, the "doubleness" of the body, an entity that is by definition a relationship between 
bilaterally symmetrical components. Indeed, in conversations about healing and sickness, I heard Haya refer to an etymological connection between omubili and ebili. At least one of my neighbors extended this symmetrical condition of bodiliness to the internal organs of the body and stated that bodies have two stomachs and two livers, as well as two arms and two legs. Still, given the limited ethnographic references that $I$ have to this phenomena and in the absence of more detailed historical linguistic evidence or explicit local commentaries on its significance, I can make only tentative claims about the "doubleness" of the body, claims that may well be be motivated by an apocryphal, if suggestive, etymology. ${ }^{7}$ In any event, Haya forms of bodiliness need not be focused strictly on a concern with duality but are characterized by experiences and actions that treat the human body as a partible totality. That is, Haya embodied practices emphasize the ways in which a complementarity of clearly internally differentiated components constitutes the viability and integrity of the human body as a unified whole. Whether or not these components are "doubled," it is the synthesis of opposed elements, I will argue below, that characterizes the body as a recognizable "whole" in Haya modes of being.

The complementarity that defines the unity and coherence of a body has a certain resonance with Haya dialectical constructions of identity as I have described them. This quality of bodiliness might usefully be contrasted, in a somewhat cursory fashion, with certain conceptions, both technical and everyday, that are prevalent in Western discourses and practices. To become "embodied" in Western discourse entails a shift in being or condition. When we say, for example, that an affliction is the embodiment of a wider social conflict (as anthropologists are wont to do) or that a charismatic figure embodies the ethos, contradictions, or struggles of his or her movement, we make an assertion about a relationship between content and form. General, pervasive, abstract qualities assume, or acquire, a concrete form when they become embodied. Ots (1994) offers a cogent criticism of this widespread understanding of embodiment as a process whereby otiose forces and abstract principles (like "culture" or "mind") take possession of, or take shape as, a body. Such an objectified, as opposed to existential, view of embodiment, he notes, "may perpetuate the clean subjectobject dichotomy of mind and body rather than helping to collapse it" (Ots 1994:117). Here I am less concerned with critiquing the analytic utility of such objectified conceptions than I am with suggesting that these conceptions are characteristically taken for granted in our understanding of embodiment. The body, in these commonplace perspectives, becomes a condensation of external forces and relations that take on an internal coherence and substance. This notion of the body as an independent thing to be seized upon lends an extremely wide range of objective forms, including abstractions, the capacity for embodiment.

Consider, for example, one of the "bodies" we can inhabit, and one of our most powerful models of embodiment: corporality and the corporation. A corporation is an entity that acts and is recognized as a body. What this attribution of bodiliness entails is the corporation's capacity for coordinating the interrelationship of its component elements (that is, for unified action) and for materializing 
or giving form to those relationships. To incorporate, then, is the act of forming an association, but it is also a means of organizing relations with an external reality that lies beyond "the body." So, for example, an element that becomes a part of such a complex whole is incorporated into it. The totality, or whole, established by incorporation is not, therefore, fixed and permanent, since this capacity for appropriation and accumulation is integral to any body so conceived; but this understanding of a body as a form that can be given to content through this process does require that a body stand against that which is extrinsic to it. Incorporation, from this perspective, is a process of rendering things as a "body," as well as appropriating things into the body: a method of making into and taking into. To embody, in these terms, is to take shape, a transition that is both a relationship - between content and form, the diffuse and the concrete, parts and wholes, as well as the external and the internal-and a process of materialization, inclusion, and accumulation.

Haya bodiliness is also very much concerned with and depends on inclusion and internalization. To "grow fat" (okugomoka), for example, is to be healthy. The claim "You have grown fat" (Wagomoka) is a praise-making compliment offered to one who looks healthy after an illness or other hardship. Similarly, the first and most certain indication of illness is losing weight, a sign that neighbors' gossip seems endlessly to interpret. The expansion and collapse of the human body - its relative ability to grasp, and thus extend into or recede from, the world-is a powerful and pervasive index of Haya aesthetics and wellbeing. At the same time, this cultural understanding of bodily expansion and constraint is experienced not through an objectified body but through an active bodiliness (i.e., in the act of growing fat or thin) that discloses the condition of the body in the world. Growing fat or thin, then, is iconic of an intrinsic connection between subject and object; it is a quality that is characteristic of an active body's orientation to an inhabited environment (Weiss 1992, 1996b). Moreover, the characteristic Haya structuring of the body as a synthesized totality suggests that the nature of these processes of internalization and expansion may be coordinated differently than the accumulative and oppositional model of "incorporation" characteristic of Western discourse which I sketched above. Haya concerns with the partibility of the human body are especially relevant to this structuring. As we shall see, partibility is manifest not just in the dynamic interaction and interpenetration of the body with its context, since the body produced through that integrative process internalizes important divisions as well.

Just as Haya constructions of totemic relations foreground problems of integrity and differentiation as intrinsic features of identity, Haya forms of embodiment also point to the difficulties of achieving an integrated whole among elements that must be differentiated (as they indeed must if they are to be complementary). The Haya term for medicinal substance, for example, is omubazi, the nominal form of the verb okubazi (to lash together, to entwine). In the context of house construction, a strong reed fiber that is used to tie bundles of bamboo into structural supports is called enbazi. Similarly, posts, whether of hearth racks or houses, when joined together (usually in pairs) are embazi. What makes 
"lashing together" different from simply "tieing" (okukinga) or even "binding" (okuzinga) is that lashing is an action that joins together, ${ }^{8}$ and thereby strengthens and secures, entities that are recognized as separate. The divisions of the body, then, are in some measure conjoined by the ingestion, application, or other use of medicines, a conjunction that creates a totality while retaining and depending on the separation between constituent components.

Other attempts to preserve, enhance, or restore well-being also invoke the partibility of the bilateral body. It is not uncommon, for example, to see Haya men and women with a series of small scars. As some of these people explained to me, these scars are produced by healers who, often in order to ward off or cure a sorcerer's attack, rub medicines into incisions that they make on their patients' bodies. These incisions, which are often paired in small parallel notches, are made at points that emphasize the symmetry of the body: between the eyebrows, at the breast bone and navel, or in the small of the back along the spine. It is also common to find such scars on a person's joints. Elbows, wrists, and knees as parts of the body not only indicate the symmetrical and partible qualities of Haya embodiment, as the bilateral position of incisions on these prominent joints suggest; they also mark points of articulation, both within the body (as, for example, the forearm articulates with the hand at the wrist) and berween the body and its world. That is, bodily joints allow for the expansion and contraction of the body itself into and as a part of the spatial orientations of a lived world. They make movement possible, are the means by which persons appropriate the world unto themselves (enclosing, grasping, and taking hold), and extend themselves into that world (moving into and out of, opening, offering up, and letting go).

The potentiality of joints to express the situated character of an active body is not a precultural or universal meaning of these parts of the body. Rather, they are specific meanings that emerge within the context of embodied Haya action and experience. Haya men and women often note, for example, that the points on the body that emphasize its symmetry are especially vulnerable to or reliable indices of illness. My friends and neighbors often reported that they could feel a fever or other disease coming on by the pain in the small of their back or between their eyes. Elbows, knees, wrists, and ankles are, again, points of vulnerability and early indicators of oncoming disease. In Haya contexts, then, these bodily loci are icons of the body's engagement with its world (Weiss 1996b; compare Munn 1986). The small of the back, the knees, and the elbows are symbolic sites at which the continuous transformations in the condition of the body in the world (as in the case of anticipating a fever, recognizing the onset of illness, and treating or preventing its appearance) become registered as aspects of the body's well-being. These specified places in Haya bodies are icons in which action and experience are both objectified and embodied. A bodily conciousness is thus objectified though the diagnosis and management of illness, practices that treat the body (and its parts) as an object in order to administer therapy. This consciousness is also embodied at these iconic positions in a subject's anticipation or recollection of suffering or their sense of susceptibility or well-being. 
These iconic points-along the axis of the body (breast bone, navel, spine), as well as joints-might be said to draw attention to what Merleau-Ponty has described as the body's ability "to make out boundaries and directions in the given world, to establish lines of force, to keep perspectives in view, in a word, to organize the given world" (1962:112). As such, they are produced through "the spatial body" (Lefebvre 1991:199), the body as the medium for inhabiting, and thereby giving definitive form and content to, spatial relations and orientations. Yet what is crucial about the bodily capacities condensed in these symbolic forms is that they are not merely general phenomenological characteristics of bodily being but are concrete forms that are characteristic of Haya bodiliness. For while the engaged character of "the spatial body" may be the existential condition of embodiment, it is precisely because embodiment is intrinsically constituted by its engagement that it can only be defined with respect to its specific, situated forms. What I am suggesting is specific about these Haya modes of embodiment is that the engaged character of the active body is clearly linked in concrete sociocultural practice and experience to the complementarities of a partible body. Haya activities that gauge and treat the engaged body (e.g., sensing the onset of disease, incising vulnerable regions, and medicating sickness) do so in terms of the complementary divisions (joints, midpoints, et cetera) internal to the body. For Haya men and women, the situation of the body in the world is realized, expressed, and acted upon through aspects of the body that concretely demonstrate its partibility. In this way, the effective articulation of a Haya "spatial body" into and as part of a lived world is simultaneously a means of conjoining and integrating-"lashing together"- that body.

\section{Single Shillings, Splitting Bodies}

Some of the more effective, and for present purposes most intriguing, modes of achieving effective bodily coherence involve the use of money and, in particular, small coins. Not only are incisions of the kind described above rubbed with medicines, but the blood or other bodily substance extracted from these incisions can be made to have healing effects through the mediation of small coins. Elsewhere I have described the therapeutic practice of coating a single coin with the drawn blood or secretions from a diseased patient and then placing this coin in a crossroads (Weiss 1993). My Haya neighbors suggested that money used in this way effects a cure because the diseased bodily substance, and thus the disease itself, will be passed from the afflicted person to any person who comes across the coin at the crossroads and then takes it with her or him. Placing the coin in a crossroads, in my neighbors' views, facilitates this illicit transmission, since crossroads are the joining together of different paths and are therefore certain to have some (human) traffic on them. Thus, the misfortunes placed at a crossroads will be removed from those who are afflicted and sent on to those who come across them. In effect, the crossroads itself objectifies this reciprocal relationship of conjunction and separation, as a place of simultaneous "coming together" and "moving apart" that is necessary to restore bodily well-being, itself a process of integration and differentiation. 
Other Haya uses of single coins suggest their contribution to bodily coherence. When a child is first given a name, for example, a small bored coin called an ekyapa is tied with a string around the child's waist. This coin is said to ensure that the child will not have any trouble suckling. Moreover, the string that is used to tie the coin also serves as a means of measuring the growth of the child. The expanding belly of the child can be demonstrated by the increasing tautness of this string, and this assures parents that their children are getting fat. A strung coin both facilitates and illustrates the child's progressive expansion and internalization. Bored coins are occasionally tied around the child's wrist or ankle, as well; as my overall argument suggests, these joints are a frequent site for placing other protective amulets. Single coins can also be used at death to rather similar effect. A corpse is laid out prior to burial, usually in the front room of the household in whose farm it will be buried. A coin of small denomination-by most accounts it must again be a single shilling-is placed on the forehead of the deceased, often tied in place by a length of string or banana bast. ${ }^{9}$ This coin, I was told, is intended to prevent the corpse from swelling up and, consequently, splitting open, a degenerative process that Haya attribute to the excessive heat of the corpse. The use of this coin to prevent splitting or bursting is similar to the practice described earlier of placing a shilling in fermenting beer to prevent the beer from "tearing" at the throats of its drinkers. In both contexts, the unified integrity of the body is emphasized as a fundamental problematic of Haya embodiment (since the body must be prevented from "splitting open" or "tearing," as opposed to other forms of discomfort and decomposition), and this problematic is addressed through the efficacy of a single coin.

\section{Evaluating Money}

To this point I have sketched a particular construction of how relationships and identity are constituted in Haya social experience. Haya sociality entails an assertion of separation and differentiation that is simultaneous with, and makes possible, synthesis and integrity. This construction of sociality is objectified and embodied-or, more correctly, provides an orientation for objectification and embodiment-in Haya sociocultural practice. This orientation is concretized, I suggest, in activities and representations that range from totemic figures to medicinal substances. One question that remains is: how does this orientation engage the phenomenal properties of the small coins that figure in many of the practices described? Why, for instance, should a single shilling be an especially effective means through which to restore, enhance, and generate a characteristic form of being-in-the-world? Posed this way, the question may sound overly narrow, if not precious; but it has broader implications that turn, I suggest, on the ways monetary forms and practices, as prominent features of wider processes of valuation, are generated as apects of Haya sociality.

The single shilling coin, and the money form more generally, has an identifiable history in Kagera, and is, I would argue, a form of historical commemoration. In examining a history of bridewealth payments, for example, Reining notes the willingness of Haya communities to incorporate ever-new forms of 
currency into these transactions; cowries exchanged in the 19th century give way to rupees and hellers under the Germans and, finally, shillings under the British colonial administration and Tanzanian national government (1972:100). The incorporation of these new forms cannot be described, however, as the simple substitution of one monetary standard for another. In contemporary Haya social practice, certain bridewealth payments, while quantitatively measured in shillings, are referred to as "nine cowries," and small snacks like sweet bananas, fritters, and samosa are frequently sold for erupia, a "rupee" being equivalent to two shillings. Indeed, the vernacular term for money or cash in Hay a communities is not the Swahili words pesa or $f e d h a,{ }^{10}$ as is the case in much of Tanzania, but hela, from the German hellers of this century's early years. These current references indicate that money and monetary transactions bear with them a trace of their own history and, in particular, a sense that the currencies of today are best measured by the standards of the past.

For the Haya, money is always evaluated with respect to its own history in Kagera and makes reference to something (i.e., the heller) that is literally absent in the present. These are features of both the forms and the values of money for Haya men and women, as they are for many African peoples (Guyer 1995:14 ff.). Moreover, there is a pervasive nostalgia surrounding both the various currencies through which money works, and monetary worth and value. Market days in rural areas often find people lamenting their economic fortunes by talking about the value of money: "It used to be," as one of my friends frequently told me, "100 shillings was real money. You could go to market and buy a shirt and a goat and many kilos of maize meal. Today, you don't get a thing." What is especially interesting about this altogether typical complaint is that it bespeaks a sense of loss and dismay which can be expressed in terms of the putatively "true" value of money. The implication of such a complaint is not only that money carries with it an evocation of the past but that the real value of money, the grounds against which transformations in monetary values may be gauged, always lies in the past.

In the Kagera region during the late 1980 s, the single shilling coin might be said to have been subject to a similarly nostalgic process. This coin was, in many respects, both a sign of disappearing value and a disappearing sign. While single shilling coins were still in widespread circulation in this region, a number of processes were beginning to make these tokens increasingly peripheral to economic life." These were times of hyperinflation, massive currency devaluations, and the concomitant introduction of ever-larger denominations of currency. (In 1989 the Tanzanian government issued 500-shilling notes for the first time [Weiss 1993].) Single-shilling coins could thus readily be taken as tangible icons of exclusion and marginality, as monies whose relevance was rapidly becoming obsolete. From this perspective, the various uses of single-shilling coins may be considered something more than a nostalgic railing against inflation; they might, in fact, be seen as attempts to revalue the grounds of monetary value itself. The increasing marginalization of the single shilling as a token of economic transactions, I am suggesting, put it in the position of "real money" from which it could address the ongoing demise of economic values. 
Haya understandings of money also provide us with insight into the implications of money and other media of value in local experiences of social transformation. The European currencies, whose histories are pragmatically remembered to this day, first entered into Haya social and economic life in significant numbers at the turn of the century. Not only did German authorities introduce rupees, they also imposed "hut taxes" that ultimately required Haya households to make use of rupees. Requiring the use of colonial currencies in Kagera was tied to overrule not just through taxation but through the production of coffee as a cash crop, which the introduction of mandatory taxes (and ultimately, mandatory coffee cultivation [Curtis 1989:89]) was intended to encourage. I have elsewhere examined the complexities of coffee in Kagera as a medium of value and meaning (Weiss 1995); but it is worth considering some important connections of coffee to colonial currencies here in order to explore the historical dimensions of coinage and money. The use of hellers and rupees may have been meant to facilitate coffee marketing, but this history was not simply a linear commoditization of Haya economy and society. Indeed, coffee was an agricultural good in the precolonial interlacustrine world, and its production and circulation in that world had many properties we might associate with the commodity form and especially with currencies that allow for the interconversion of different forms of value (Hart 1986). As a medium of exchange during the 19th century, coffee was routinely transacted for valuables, especially fine barkcloths from the Baganda and Banyoro kingdoms to the north. Coffee, like coinage, also provided a means of linking local household productivity with the efficacy and authority of the state. Royal clans collected annual tribute from their clients and commoners in coffee, who often had coffee trees that "belonged to the king" set aside for such purposes. At the same time; coffee trees were intimately associated with domestic viability and well-being; householders' amagala (life force) was bound up with their coffee, to the extent that the death of a coffee tree was an omen of its owners death (Hyden 1969:82).

The historical connections between coffee and coins in Haya communities, as tokens of both circulating wealth and centralized power, may also be considered from the perspective of embodiment as a process of valuation. As indicated, Haya coffee trees were integral aspects of the bodily strength of their cultivators. Moreover, in precolonial contexts coffee cherries (i.e, the seed pods containing the two beans that are roasted before grinding) were dried and cooked with spices, to be offered as informal, chewy gifts to friends and guests, a practice that continues in the present day. In addition, such coffee cherries were important to bodily dimensions of Haya sociality. In the rites and relations of blood brotherhood, for example, a single coffee cherry was coated with blood drawn from each navel of the prospective blood brothers. Each brother would then chew one of the beans within the blood-marked cherry. In this way, my neighbors asserted, men of different clans would use the concrete model of two seeds within the single cherry to demonstrate through their performance that they were distinct men of "one blood" (see also Beattie 1958). Such practices indicate that there are important historical connections in the embodied experience 
of value manifest both in the use of coffee to promote the construction of bodily connections between distinct bodies and in contemporary Haya uses of coins to promote the integrity of the differentiated human body.

What makes these bodily practices that deploy coinage and currency in order to effect bodily integration especially noteworthy are the ways in which they run counter to a host of meanings and qualities commonly associated with money in contemporary quotidian Haya experience. Money, for example, is often characterized as an especially hot medium. Expanding commodified transactionsin arenas as diverse as the sale of distilled (and occasionally explosive) banana gin and the purchase of uncultivated tracts of farmland in regions of Kagera renowned for being especially arid and unshaded ${ }^{12}$ - are commonly experienced and described as remarkably hot. ${ }^{13}$ Indeed, the comments of one of my friends who described the efficacy of the shilling in the beer in terms of its "acidity" recall these thermal properties, as acid itself is a substance that many Haya associate with superheated forms of energy and power like electricity and gasoline. Given these prevalent and highly charged symbolic connections between monetized transactions and excessive heat, it is surprising to find money used in some of the ways I have described. For if money is a token of heated commerce, the particular uses of certain individual coins are explicitly said to diminish the effects of heat: these single shillings restore the "fresh/raw" qualities of banana beer and prevent a corpse from overheating and bursting. The apparent inversions of such critical symbolic qualities may be linked, I would argue, both to the singularity of these monetary tokens and to the contexts of action (and transaction) in which they figure. In short, the significance of these single shillings derives from the ways in which they are made to objectify specific Haya notions of value.

In his account of the objectification of value, Simmel argued that the radical implications of money and monetized transactions could be described in terms of an ever-encompassing reduction of qualitative to quantitative values. ${ }^{14}$ By permitting a shift in the focus of social value from the personal bonds that organize the exchange of objects to the impersonal calculus of a price, money facilitates the dissolution of meaningful distinctions between material goods. The idea of price itself, made possible by monetary measurement, gives rise to the absolute commensurability of all values, as the value of anything can be expressed in terms of a common scale of prices. Moreover, market values and quantification, according to Simmel, are actually enhanced by the presence of money. That is, money is not merely the instrument of calculation but is itself an inexhaustible source for quantifying values. Money itself, says Simmel, exhibits an "unconditional interchangeability," an "internal uniformity that makes each piece exchangeable for another," and it is this feature of money that makes possible the "interchangeability" of all objects, once they are evaluated in terms of money (Simmel 1978[1900]:441). Money is calculation and commensurability itself and may be taken as iconic of a more general elimination of qualitative distinctions in social life. For Simmel, money is an embodiment of the quantifiable and impersonal, an "utterly colorless" medium that bleaches out qualitative values entirely (1978[1900]:377). 
There are, of course, innumerable counterexamples-from birthday greetings written on legal tender to the taint of blood money - that challenge this effacement of social bonds and cultural meanings in our actual experience of money. Greenbacks, sawbucks, and blueies are only some of the more colorful monikers of our "colorless" money. ${ }^{15}$ Simmel himself recognized these widespread usages but dismissed them as atavistic "sentimentalities" that would ultimately fade away (1978[1900]:444). Yet at the end of the 20th century these practices may seem less residual and more like intrinsic possibilities of all monetary systems. We can push these arguments about the qualitative dimensions of money further still. The Haya practices that make use of coins indicate that qualitative meanings and values do not simply persist in the face of quantifiable monetized transactions. Nor are cultural qualities continuously created simply in order to put a sociable face on otherwise faceless moneys. Rather, the very system of quantification and calculation as it is realized in the ways that people actually make use of money in buying and selling is always tied to a concrete set of currencies and thus is never a purely abstract, quantitative, and numerical system. That measurement, interchangeability, and calculation are expressed and acted upon in terms of specific currencies that employ a standard set of denominations combines quantity with quality and lends certain quantitative measures specific qualitative values. It is not merely the "colorful" dimensions of coins and notes that allow for symbolic elaboration, for all currencies objectify quantitative measures in concrete forms. The particularities of these specific forms constitutes a qualitative dimension of all monetary systems.

In the abstract, any price can be expressed as a quantifiable value: as six dollars or 27 cents or 7,060 shillings or 95 francs. But in the course of routine transactions, when buying and selling, such prices are expressed as a particular combination, out of many possible combinations of concrete currency: for example, 565 shillings made from two 200 -shilling notes, one 100 -shilling note, four 10-shilling coins, and five 5-shilling coins. Each of these coins and notes is a denomination in terms of which prices can be measured and equivalences can be calculated. It is also important to note, however obvious it may appear, that such denominations are also standard units of currency that make monetary practices-transaction, combination, and divisibility-possible. These combinatory possibilities are important, for they allow for the introduction of qualitative differences between quantitatively identical values. That is, a 100 -shilling note is the equivalent of two 50-shilling notes, but it is also qualitatively different from them, as are they from the five 20 -shilling coins that could also be used to express the equivalent value. Any unit of currency-whether a 20-dollar bill, a ten-pound note, or a five-shilling coin--is therefore an expression, indeed an objectification, of both quantitative and qualitative values. Such monetary units are means of measurement and calculation, as well as material forms through which qualitative differences in values are transacted, combined, interchanged, and concretized in social practice.

These features of currency systems, and of denominations as standardized units of monetary practices, bring us back to those single shillings that feature 
so prominently in the Haya activities already described. For if all currency is issued in standard denominations that allow numerical prices to be rationally calculated while also providing concrete units in terms of which social actions and transactions are carried out, a single-shilling coin may be seen as a truly "unique" form for combining these possibilities. In the Tanzanian economy, the single-shilling coin is a denomination through which values can be exchanged, and it is also the standard unit of currency in terms of which value may be quantified, measured, and calculated. That is, since all prices in the money economy are figured in terms of the value of a shilling, the single-shilling coin is simultaneously a qualitative unit of transaction and the currency that makes measurement possible in this system. Singularity in both instances is a feature of the qualitative, as well as the quantifiable value, of the shilling coin. This capacity as the only unit of currency that is both a form of asserting qualitative differences (in this respect, like any other denomination) and the grounds of quantifying value gives single-shilling coins a unique position in this system. This uniqueness may be seen as a position of hierarchy and power and may help account for its inversion of the more common Haya symbolic attributes of money. The single-shilling coin is the tangible, concrete, oft-exchanged currency that may be a paltry sum but is nonetheless what makes it possible to measure the price of anything.

\section{"Priceless" Coins and Contexts of Transaction}

Single-shilling coins may be unique in the system just described, but there is nothing unique about this monetary "logic." In the United States, for instance, ten dollars found by chance might make us a bit wealthier, but a single cent picked up off the ground is a "lucky penny." The same is true of pennies thrown into wishing wells and single dollar bills framed behind the counter of a diner or drugstore. Each of these "special moneys" is a "unique" currency in the terms I have spelled out, a singular form that is both a standard measure and concrete means of exchange. Yet while these distinctive ways of valuing money may be potentials, if not realizations, of all currency systems that make use of standard denominations, particular local forms of valuation must be linked to the kinds of practices-whether hung on a wall, put in a pocket, or dropped in brewing beer-in which these distinctively valued currencies are engaged. I would suggest, for example, that in U.S. practice the "fetishization" of single dollars and pennies is related to what Zelizer (1994) describes as the personalized sentimentalization of gifted moneys. These unique currencies are appropriated as vehicles for the expression of intensified, individual attachment; a single dollar bill effectively condenses and displays the singular time and space of an enterprise's inauguration, and pennies carry the specificities of personalized wishes into wells. It is as though the uniqueness of the currency is a correlative, even an icon, of the individuated person to whom it is attached.

I would argue that the ways in which single shilling coins are transacted or, more precisely in the Haya case, withheld from transaction constitutes the way in which these coins come to objectify local forms of value. Moreover, these 
contexts of transaction, as aspects of wider processes of social and human action, might also be seen to establish significant connections between Haya understandings and constructions of valuation and embodiment. Like all coins, single shillings are mediums of exchange, and it is their relation to processes of exchange and transaction that gives these single shillings their unique value. In each of the Haya practices described, the coins that are used to restore the integrity of bodies suffering from splitting, tearing, or similar affliction are conspicuously removed from transaction. A coin tossed in a beer canoe, tied to an infant's waist, or placed on a corpse's forehead ceases to function as a medium of exchange. The shilling coated with a patient's blood might seem to be an exception to this pattern, since placing this coin in the crossroads is meant to ensure its circulation among others. Yet it is precisely the way in which this coin circulates, I would argue, that demonstrates that it does not constitute part of a transaction. The purposefully abandoned shilling is not offered in exchange for health, wellbeing, or any other quality that the patient hopes to acquire. This single shilling is certainly not the price of his or her health care; rather, the coin itself carries and conveys the affliction with which it has been tainted. In such a practice, the shilling does not serve as an equivalent value of the disorder that makes this bodily condition commensurable with other values and objects; instead, the coin is identified with the condition. We might contrast these practices to those cited in the U.S. case, where the unique currency serves to extend the connection of a penny or dollar to a particular person even after that person no longer possesses it. In the Haya case, the single shilling's attachment to a person is, instead, what allows elements of the person to become detached from them. This special currency is a token not of transaction but of transmission or conveyance, for which nothing can be received in return. Indeed, the contrast between transaction and conveyance is fundamental to this practice. For while "sending out" illness with this coin is often seen as unscrupulous, and may even be described as a kind of sorcery, the attempt to pay someone else to take on your affliction would be seen less as an act of malice than one of stupidity!

None of these special currencies, according to the accounts or actions of any Haya man or women I met, constitutes payment for anything, although the ways they are put into practice is held to render a service. These coins, then, do not interchange with other currencies, products, goods, or any other commodity forms. More fundamentally, by being withdrawn from transaction these particular single shillings cease to function as measures for the value of other objects and therefore as a means of expressing the commensurability of all monetary values. In short, the value of these shillings withheld from transaction no longer expresses, or has, a price. Such "priceless" coins, engaged in social practices in these specific ways, are no longer engaged in transactions and, further, do not facilitate the interchange and interconvertibility of all objects in terms of a single scale of values. If money, as Marx said, is the epitome and apotheosis of the commodity because money assumes a "universal equivalent form" that permits the reduction of all specific values to a common expression in terms of price (1906:81; see also Simmel as cited above), then currency as it is used in these 
Haya practices would seem to interrupt this reduction to a common form of value. Instead of facilitating universal equivalence, these practices emphasize the specificity, indeed peculiarity, of these monetary forms of value. Again these practices draw our attention not to the interconnection and commensurability of the wide, perhaps universal, array of values that money can objectify but to the singular qualities of this particular objectification of value.

It is precisely this singularity, a quality that becomes objectified in the form of the single shilling coin through its pointed withdrawal from the world of commerce and transaction, that makes these tokens relevant to Haya attempts to shore up bodily well-being. In removing such coins from transaction, the Haya construct and objectify an alternative form of value that literally has no equivalent, a value that is incommensurable and indivisible. We should not be surprised, then, to find that many Haya understand an objectification of this potent form of singular value to have the therapeutic effects it does. For, as I have described in detail, integrity and coherence are a fundamental problematic in Haya constructions of embodiment, a problematic that is made all but transparent in the concerns with splitting corpses and throat-slashing beer. It is the "uniqueness" of what is always a nonunitary body that requires attention in these instances, and these revaluations of the single-shilling coin are literally made to address this concern.

\section{Conclusions}

Let me summarize the claims I have made and draw attention to what I think are some of their more significant implications in contemporary Haya sociocultural life. I have detailed a model of Haya sociality that underlies sociocultural processes of embodiment, objectification, and valuation. In particular, I have attempted to demonstrate the interconnected nature of these constitutive processes, of the ways, for example, that Haya concerns with bodily integrity and differentiation are equally features of their understanding of totemic identities and the values of transaction and money. Embodiment and valuation, then, are reciprocal dimensions of a process in which sociocultural meanings are concretized. The interpenetration of these processes might be further demonstrated-and some loose ends tied up-by considering again the crisis faced by unsuccessful brewers. The young girl's relationship to the resolution of this crisis, a relationship that exemplifies the characteristic differentiation that is intrinsic to Haya constructions of integrity, may also be seen to exhibit important forms of value. In this respect, her relationship to the shilling itself is also relevant. The coin thrown in the unpalatable beer, I have argued, concretizes a kind of singularity, a quality that is constructed by removing this currency from the give and take of interchanging commensurate values. And similar qualities and potentialities might be said to be characteristic of this female child.

It is important to point out the kinds of potential that this girl embodies, and the kinds of bodies that women potentiate, in order to specify the connections between the different objectifications of value under discussion. Virginity lobugole) continues to be a recognized status in Haya communities, and according to 
Reining, being married as a virgin bride (an omugole) is "the most important social and psychological event in a Haya woman's life" (1973:210). A virgin bride clearly embodies an array of sociocultural potentialities. The heightened, rigorous attention that the matrikin of a betrothed woman pays to ensure her marriage as a virgin indicates that this bodily condition has implications for the establishment and demonstration of all of these women's identities. I was often told, for example, that a betrothed woman who does not display the modesty and restraint (obugole) that are appropriate to her situation will lead people to accuse her mother and her father's sisters of raising their child poorly (Weiss 1996b). Further, it is the virginity of a husband's wife that makes it possible for him to be "released from boyhood" (Reining 1973:210). Thus, the mature masculinity of husbands, as well as matricentric nurturance and worthiness of the sort demonstrated by mothers and fathers' sisters, are all qualities that are potentiated by the bodily condition of the omugole.

It is crucial, however, to recognize that as much as "virginity" embodies a certain kind of potential and is therefore a condition that continues to be of concern in Haya communities, the young girl carried over the beer canoe would never be described as a "virgin." An omugole is a woman who has the potential for marriageability and whose body gives rise to the possibility of transformations, in others as well as herself, that are the focus of Haya men's and women's concerns with virginity. Yet this female child has no such potential. She is a mere girl, an omwisiki; indeed, it is a characteristic form of joking for Haya grandfathers to call their baby granddaughters omugole wange (my virgin bride), a joke made possible by the irony of calling this child something she so clearly is not. ${ }^{16}$ Furthermore, it is the bodily condition characteristic of young girls, and not of virgins, that Haya men and women would be likely to characterize as "without flaws"; for the "flaws" to which my brewing neighbors referred in all probability had less to do with violations of virginity than the onset of menstruation, which is, after all, a greater threat to good beer. That these "flaws" concern menses may be supported linguistically. To menstruate in the Haya language is okushoba. When Haya speakers use Swahili, the causative form of the verb, okushobya, is translated as kukosa (to be mistaken, flawed, in error). In colloquial Haya speech, to menstruate is okuzila (to avoid [as discussed above]), a term that does more than simply confirm widespread anthropological observations about the connections between avoidance and menstruation. For in order to grasp the significance of Haya connections between menstruation and avoidance, we must appreciate Haya sociocultural constructions of avoidance. The understanding of menstruation as a phenomenon informed by these cultural notions of avoidance indicates that a girl who has not yet begun to menstruate may not yet embody the kinds of internalized divisions characteristic of Haya avoidance.

The body of this female child is, I would therefore suggest, "without flaws," as well as undivided and singular, at a number of levels. Such a young girl has clearly been withheld from human interchange and circulation (just like the single-shilling coin that goes in the beer) and would never be considered eligible 
for such interaction. More fundamentally, her bodily mode of being-in-theworld does not yet manifest the characteristic Haya forms of relationality-unity conjoined with differentiation, integrity with alterity-that make such human interchange possible. As a pristine body, then, the young girl remains a form of pure potential in terms of sexuality, reproductivity, and sociality itself. And just as the relatively "worthless" single shilling is nonetheless the unit that allows all monetary increments to have a specific value, the presexual, premenarchal female body is also the grounds of generative social relations, a "flawless" form that contains within it the potential for sexuality and reproductivity, affinity, and descent. As a daughter, brother's child, or possible spouse, a woman's body and conduct will have transformative effects on others. It is therefore important to recognize that the young girl's possibilities as a body are as yet unrealized and are not yet even oriented to sexual, affinal, maternal, or agnatic connections. But she retains her singular value as a body that "has no flaws," a value that derives not from its relation to others but that embodies a form of value in itself, much as the single coin becomes a "priceless," singular object.

I would be willing to acknowledge the purely speculative nature of these suggestions and to restrict their significance strictly to their suggestive possibilities, if it were not for the fact that Haya men and women often talk about young girls, and indeed the value of young girls, in remarkably similar terms to those I am using here. A good deal of Haya discourse surrounding the collapse of enduring social relationships and practices turns to discussions of female sexuality and, in particular, the relation of women, virginity, and sex to money (see also Weiss 1993). When people decry, as they often do, rising rates of prostitution, as well as HIV and the contemporary uncertainties of marriage and sexuality more generally, young girls are often singled out for particular criticism. The foolish behavior of such young girls, according to many men and women, is their failure to recognize their own value. As a common saying (in vernacular uses of Swahili in the Kagera region) goes, "Thamani ya msichana ni usichana wake" (The value of a young girl [msichana] is her "young girl-ness" [usichana]). Here the term used to identify the abstract value of a young girl is derivative of the term for young girl itself. What this makes clear is that a female child embodies value in and of herself. From the perspective of Haya bodiliness developed here, a young girl's body is clearly removed from the interchange and interaction of sexual life and does not yet demonstrate outward signs of reproductive capacity and social relatedness. Her body in itself is coherent and integrated: the antithesis of perhaps of a "splitting" corpse. The young girl's body is a body that has "no flaws" and thus epitomizes a potentially powerful resolution to the characteristic Haya problematics of social existence. The value she embodies is, in a word, unique.

\section{Notes}

Acknowledgments. The research upon which this article is based was made possible by a Fulbright-Hays doctoral dissertation fellowship. The Tanzanian National Institute for Science and Technology (UTAFITI) enabled me to live and work in 
Tanzania. I am also especially grateful for the tremendous generosity of Severian and Anatolia Ndyetabula. Becky Popenoe and Amy Stambach offered generous, important suggestions on the very earliest drafts. I must thank the participants of the Eleventh Satterthwaite Colloquium on African Ritual and Religion for their thoughtful discussion of my paper. In particular, I want to thank Dick Werbner for his kind invitation to Satterthwaite and Manchester and his enthusiasm for my paper. Thanks as well to Misty Bastian, Jean Comaroff, and Julie Corsaro for their important suggestions, and to Dan Segal for his excellent editorial skills. Special thanks to Ned Alpers for providing the shilling coin. Lastly, this article is dedicated to Ezra Weiss, whose gestation coincided with (but actually took less time than) the preparation of this article.

1. Just over one million Haya live in the Kagera region, located in northwestern Tanzania. Haya kingdoms in the precolonial era were integrated into the interlacustrine political economy, dominated (at different times) by the Nyoro and Ganda in Uganda to the north; the interlacustrine region has broader sociocultural and historical connections to the indigenes of $R$ wanda and Burundi to the west and southwest as well. Haya villages in the rural areas of Kagera, the primary site of my research on which this article is based, are composed of a number of family farms. These farms are also places of residence, and all households occupy farmland. All of the farms within a village lie immediately adjacent to one another, so that the village as a whole is a contiguous group of households on perennially cultivated land. These residential villages are dispersed across and clearly contrast with open grassland. The primary produce of Haya family farms are perennial tree crops, bananas, which provide the edible staple, and coffee, which provides the principal source of money. While coffee remains the most significant source of a rapidly declining cash income in Kagera today, this cash is filtered through the Haya community in an informal economy (biashara ndogo ndogo in Kiswahili) of marketing local produce, household commodities, and new and used textiles and clothing at local weekly markets, as well as plenty of beer.

2. In this article the words I have cited in translation are from either of two languages: Oluhaya, the vernacular of most Haya villages in Kagera, and Kiswahili, the of ficial and national language of Tanzania and a language in which virtually all Haya men and women are fluent. These language are referred to as "Haya" and "Swahili" throughout the text. Unmarked translations are from Haya, and in those cases where I have indicated that the words are Swahili, or have given both Haya and Swahili terms, the Swahili is preceded by an $S$.

3. See Jackson's (1989:122-124) critique of strictly "symbolic" approaches to the body; see Scheper-Hughes and Lock 1987 for an excellent review of bodiliness as a foundation of political projects.

4. As distinct from simply "welcoming" (okunyegeza) or "bringing in" (okutaa), okualika is used only to refer to these specific activities.

5. See Weiss 1996a and $1996 \mathrm{~b}$ for a more detailed discussion of the significance of surfaces and appearance in Haya communities.

6. This relation is widespread in Bantu languages-for example, mwili and mbili in Kiswahili.

7. The Inter-territorial Language Committee's Swahili English Dictionary also makes the following observation: " $m$-wili is a possible form of -wili, twofold, double, two, and so perh. [sic] of the body as characterized as a pair of limbs, symmetrical sides" (Inter-territorial Language Committee for the East African Dependencies 1969:322).

8. The significance of "binding" is especially important in all manner of Haya sociocultural processes. "To bind" an event, a place, or a person secures it in an 
especially powerful way by defining a specific set of spatial orientations that both establishes an interior fixity and viability and excludes an external penetration (Weiss 1996b; see De Boeck 1994 on "tying" in aLuund communities as a similarly powerful act). Of course, in Haya communities medicines that "lash together" may also be used in "binding" rites; the spatial implications of both acts complement one another in many respects, which, I would argue, suggests the widespread importance of creating integrity and cohesion while simultaneously assuring and defining differentiation as dimensions of Haya sociality.

9. I also heard from some Haya friends that mourners, especially lineal descendants of the deceased, will also tie a shilling to their foreheads for a period of time. This suggests an important identification of the mourners' bodies with the corpse; but I was unable to elicit commentaries on the significance or effects of this practice.

10. Pesa is a term used throughout Tanzania for money in general, a term that also has its origins in historical East African currencies. Pesa is the Swahili term for pice, 64 of which constitute a "rupee" (Inter-territorial Language Committee for the East African Dependencies 1969).

11. According to Peter Pels (personal communication), single-shilling coins were increasingly difficult to come by in coastal regions of Tanzania during the late $1980 \mathrm{~s}$.

12. Banana gin (enkonyagi) must be clearly distinguished from the olubisi described above, whose very name means "fresh, raw, uncooked." This thermal contrast is crucial to the substance and effects of these brews, as well as to their monetary implications; while "beer" is fermented without being heated, banana gin is produced by boiling this "cool" substance in order to distill it. This banana gin fetches a much higher price and is much more extensively associated with production for sale than is olubisi. (See Weiss 1996b for extended discussion of this contrast.)

13. I have described the thermal qualities of money and of commoditized transactions more generally in Haya discourse at length elsewhere (Weiss 1993, 1996b). See also Shipton 1989 on similar qualities in Luo encounters with money.

14. See Zelizer (1994:6 ff.) for a discussion of this understanding of money in social theory of the late 19 th and early 20 th centuries more generally.

15. The symbolism of Haya names for currency, which cannot be detailed here, are described more thoroughly in Weiss 1993.

16. Alternate Haya generations joke with one another, and the joke consists of recognizing grandchildren and grandparents as possible marriage partners; in fact, Haya do express a preference for marrying members of their grandparents' clan, if not their actual grandparents.

\section{References Cited}

Beattie, John

1958 The Blood Pact in Bunyoro. African Studies 17:193-203.

Bourdieu, Pierre

1979 "The Disenchantment of the World" in Algeria 1960. Cambridge: Cambridge University Press.

Carlson, Robert

1989 Haya Worldview and Ethos: An Ethnography of Alcohol Production and Consumption in Tanzania. Ph.D. dissertation, anthropology department, University of Illinois. 


\section{Csordas, Thomas}

1990 Embodiment as a Paradigm for Anthropology. Ethos 18:5-47.

1994 Embodiment and Experience: The Existential Ground of Culture and Self.

Cambridge: Cambridge University Press.

Curtis, Kenneth

1989 Capitalism Fettered: State, Merchant and Peasant in Northwestern Tanzania,

1917-1960. Ph.D. dissertation, history department, University of Wisconsin.

\section{De Boeck, Filip}

1994 Of Trees and Kings: Politics and Metaphor Among the aLuund of Southwest-

ern Zaire. American Ethnologist 21:451-473.

Devisch, Renaat

1985 Symbol and Psychosomatic Symptom in Bodily Space-Time. International

Journal of Psychology 20:589-616.

Gregory, Christopher

1982 Gifts and Commodities. London: Academic Press.

Guyer, Jane

1995 Money Matters: Instability, Value and Social Payments in the Modern History of West African Communities. London: James Currey. Hanks, William F.

1991 Referential Practice: Language and Lived Space in a Maya Community.

Chicago: University of Chicago Press.

Hart, Keith

1986 Heads or Tails: Two Sides of the Coin. Man 21:620-644. Hyden, Goran

1969 Political Development in Rural Tanzania: Tanu Yajenga Nchi. Nairobi: East African Publishing House.

Inter-territorial Language Committee for the East African Dependencies

1969 Swahili-English Dictionary. New York: Saphograph Company. Jackson, Michael

1989 Paths Towards a Clearing. Bloomington: Indiana University Press. Karp, Ivan

1980 Beer Drinking and Social Experience in an African Society: An Essay in Formal Sociology. In Explorations of African Systems of Thought. Ivan Karp and

C. Bird, eds. Pp. 83-119. Washington, DC: Smithsonian Institution Press. Lefebvre, Henri

1991 The Production of Space. Donald N. Smith, trans. Cambridge, England: Blackwell.

Lévi-Strauss, Claude

1962 Totemism. Rodney Needham, trans. Boston: Beacon Press. Marx, Karl

1906 Capital, A Critique of Political Economy. New York: Charles H. Kerr and Company.

1959 Theses on Feuerbach. In Marx and Engels: Basic Writings on Politics and

Philosophy. Lewis Feuer, ed. Garden City, NY: Doubleday. Merleau-Ponty, Maurice

1962 The Phenomenology of Perception. London: Routledge and Kegan Paul. Munn, Nancy

1986 The Fame of Gawa. London: Cambridge University Press. 
Ots, Thomas

1994 The Silenced Body - The Expressive Leib: On the Dialectic of Mind and Life in Chinese Cathartic Healing. In Embodiment and Experience: The Existential Ground of Culture and Self. Thomas Csordas, ed. Pp. 116-136. Cambridge: Cambridge University Press.

Reining, Priscilla, ed.

1972 Haya Kinship Terminology: An Explanation and Some Comparisons. In

Kinship Studies in the Morgan Centennial Year. Washington, DC: Anthropological Society of Washington.

1973 The Haya of Northwest Tanzania. In Cultural Source Materials for Population

Planning in East Africa, vol. 2. Angela Molnos, ed. Pp. 204-210. Nairobi: East African Publishing House.

Scheper-Hughes, Nancy, and Margaret Lock

1987 The Mindful Body. Medical Anthropology Quarterly 1:6-41. Seitel, Peter

n.d. The Bachwezi in Art and History: Who is Mugasha in Hayaland? Paper presented at the annual meeting of the African Studies Association, Madison, WI, October 1986.

Shipton, Parker

1989 Bitter Money: Cultural Economy and Some African Meanings of Forbidden

Commodities. Washington, DC: American Anthropological Association.

Simmel, Georg

1978[1900] The Philosophy of Money. Tom Bottomore and David Frisby, trans.

London: Routledge and Kegan Paul.

Taylor, Christopher

1991 Milk, Honey and Money. Washington, DC: Smithsonian Institution Press.

Turner, Terence

1994 Bodies and Anti-Bodies: Flesh and Fetish in Contemporary Social Theory. In

Embodiment and Experience: The Existential Ground of Culture and Self. Thomas

Csordas, ed. Pp. 27-47. Cambridge: Cambridge University Press.

Weiss, Brad

1992 Plastic Teeth Extraction: The Iconography of Haya Gastro-Sexual Affliction. American Ethnologist 19:538-552.

1993 'Buying Her Grave': Money, Movement, and AIDS in Northwest Tanzania. Africa 63:19-35.

1995 La Nourriture qui ne rassassie jamais: Une histoire sociale du café haya. Note de recherche invitée dans "Frontières Culturelles et Marchandises." David Howes, ed. Anthropologie et Sociétés 18:91-100.

1996a Dressing at Death: Adornment and Temporality in Buhaya. In Clothing and Difference: Embodied Identities in Africa. Hildi Hendrickson, ed. Durham, NC: Duke University Press.

1996b The Making and Unmaking of the Haya Lived World: Consumption and Commoditization in Everyday Practice. Durham, NC: Duke University Press.

Zelizer, Vivian A.

1994 The Social Meaning of Money: Pin Money, Paychecks, Poor Relief and Other Currencies. New York: Basic Books. 